\title{
MULTIDÃO E VULNERABILIDADE: POETAS E NOVAS POLÍTICAS DE SUBJETIVAÇÃO
}

\section{MULTITUDE AND VULNERABILITY: POETS AND NEW POLITICS OF SUBJECTIVATION}

\section{Sandro Ornellas*}

RESUMO: O texto estuda a figura do poeta como um tipo de crítico cultural. Inicialmente, articula-se o ethos do poeta a partir de um lugar de enunciação que ele ocupa diante do campo literário, resultando em processos de subjetivação ligados a certas práticas político-culturais contemporâneas. Depois, toma-se a noção de vulnerabilidade, articulada a políticas discursivas de gênero, para se pensar um pouco dessas políticas discursivas contemporâneas que têm no poeta e na poesia uma das suas figuras críticas exemplares. PALAVRAS-CHAVE: Multidão. Vulnerabilidade. Poetas. Subjetivação. Crítica da Cultura.

ABSTRACT: The text examines the figure of the poet as a kind of a cultural critic. Initially it articulates the ethos of the poet, departing from a place of enunciation that he occupies before the literary field, resulting in processes of subjectivation linked to certain contemporary political-cultural practices. Then it approaches to the notion of vulnerability, articulated to gender political speeches, in order to think a little bit about these contemporary discursive policies

\footnotetext{
* Universidade Federal da Bahia (UFBA), Salvador, Bahia. Doutor em Letras e Linguística (Teorias e Crítica da Cultura e da Literatura) na Universidade Federal da Bahia (2006). Professor Adjunto de Literatura Portuguesa e Estudos Comparados de Literaturas de Língua Portuguesa do Departamento de Letras Vernáculas no Instituto de Letras. E-mail: ssornellas@gmail.com
} 
that use the poet and poetry as one of its exemplary critic figures. KEYWORDS: Multitude. Vulnerability. Poets. Subjectivation. Cultural Critique. 


\section{MULTIDÃO E VULNERABILIDADE: POETAS E NOVAS POLÍTICAS DE SUBJETIVAÇÃO}

Por motivos pessoais, mas sobre o modo coletivo de vida.

Vladímir Maiakóvski apud JAKOBSON (2006: 44)

\section{POETA COMO SUJEITO DA MULTIDÃO}

Em artigo do livro A ética da aventura, Lêdo Ivo se intrigou com uma pergunta que um dia lhe dirigiram: "O senhor é poeta e escritor, não é verdade?” (1982: 41). Tendo ele escrito e publicado tanto livros de poesia quanto livros de prosa, lança-se a tentar entender os meandros dessa dupla caracterização que recebe e que percebe ser muito mais comum do que poderia parecer a primeira vista, tanto entre leitores quanto entre os próprios escritores. É daí que elabora a pergunta que intitula seu artigo: "Poeta é escritor?". Sem a intenção de responder definitivamente à pergunta, ele se entrega a reflexões que privilegiam sobretudo as diferenças e semelhanças de linguagem e criação (como criador que era), destacando o fato de que há prosadores que se valem intensamente "dos frêmitos e emoções específicas do poema" (1982: 42), assim como "há poemas dotados de enredos e figuras” (1982: 43). Suas elucubrações, no entanto, revelam a inquietação de 
que algo na poesia não se deixa capturar pela prosa; ou ainda, mais radicalmente, de que haveria uma "diferença entre Poesia e Literatura" (1982: 42), o que justificaria a dupla caracterização que recebeu e que é tão sintomática do senso comum. Mas é sua conclusão que interessa, ao fim e ao cabo, usar como farol a este artigo, pois o escritor, junto com o leitor, o crítico, o jornalista literário, o editor, professores, alunos, etc. são as figuras compõem o campo literário (comporia o poeta esse campo?). De um longo verso de Paul Claudel - citado por Ivo - a propósito da chegada do jovem Rimbaud a Paris - "Eis, pela primeira vez, quem desembarca, e está entre os horríveis homens de letras e nos cafés"1 - conclui Lêdo Ivo que "o poeta é um estrangeiro entre os homens de letras" (1982: 44).

O que poderia soar como uma excessiva e também muito comum mistificação do poeta na voz de alguém como Ivo, surgido na conservadora Geração de 45, ganha ares de ironia político-cultural na voz de outro poeta, desta vez do início do século XXI, Eduardo Sterzi. Ele é citado no pequeno ensaio sobre valor e literatura chamado $O$ preço da poesia, em que a autora, Paula Glenadel, toma do Fedro, de Platão, a analogia do poeta com a cigarra e de La Fontaine, na fábula da cigarra e da formiga, a analogia da cigarra com o sujeito incapaz de qualquer previdência financeira, ao contrário da formiga. Depois de sugerir com essas referências a imagem do poeta como alguém inadequado a um mundo cuja produção de valores financeiros, culturais, políticos e morais ocorre cada vez mais fundida à lógica capitalista (não custa lembrar que La Fontaine é do século XVII, antessala de Revolução Industrial), a ensaísta conclui com uma quadra do "novíssimo" poeta. Nela, intitulada "Poetas", a ambígua relação dos poetas com o presente é tratada ironicamente: "os poetas são todos uns merdas / só pensam em dinheiro / matá-los seria perfeito / não fossem a sujeira e os berros" (STERZI apud GLENADEL, 2011: 46).

A incapacidade do tempo presente em matar os poetas - apesar da sua aparentemente óbvia inutilidade - revela algo da relação que nosso mundo possui com eles e que Giorgio Agamben também percebeu de maneira

1 O verso original de Paul Claudel - citado por Ivo e traduzido por mim - é: "Le voici pour la première fois qui débarque, et c'est parmi ces horribles hommes de lettres et dans les cafés" (CLAUDEL apud IVO, 1982: 44). 
muitíssimo precisa: o poeta é o modo de subjetivação por excelência do que sempre é contemporâneo, justo por não estar nem totalmente incluído nem totalmente excluído do seu próprio tempo: "o poeta, enquanto contemporâneo, é essa fratura, é aquilo que impede o tempo de compor-se e, ao mesmo tempo, o sangue que deve suturar a quebra" (AGAMBEN, 2009: 61). Esse argumento nietzscheano de Agamben, pela extemporaneidade como maior definidora da contemporaneidade, aparece também quando ele afirma que "um bom exemplo dessa especial experiência do tempo que chamamos contemporaneidade é a moda", pois "o estar na moda (...) comporta um certo 'agio', uma certa dissociação, em que a sua atualidade inclui dentro de si uma pequena parte do seu fora, um matiz de démodé" (AGAMBEN, 2009: 66 e 68). Disso se pode deduzir, então, que o poeta é o "fora de moda" que, por isso, lança a moda? Por mais que soe estranho e paradoxal, explica de certa forma o que o poema de Sterzi diz ironicamente sobre a impossibilidade do presente em matar os poetas. Seus berros e sujeira provocariam um terrível mal-estar e culpa, pois a anacrônica inutilidade da poesia e dos poetas é tão necessária a toda e qualquer sociedade, mesmo àquela em que as pessoas (e não os poetas) "só pensam em dinheiro". Como confessou João Cabral em "O artista inconfessável":

Fazer o que seja é inútil.

Não fazer nada é inútil.

Mas entre fazer e não fazer

mais vale o inútil do fazer.

Mas não, fazer para esquecer

que é inútil: nunca o esquecer.

Mas fazer o inútil sabendo

que ele é inútil e que seu sentido

não será sequer pressentido,

fazer: porque ele é mais difícil

do que não fazer, e dificil-

mente se poderá dizer

com mais desdém, ou então dizer

mais direto ao leitor Ninguém 
que o feito o foi para ninguém.

(MELO NETO, 1994: 384).

É desse poema que talvez Paulo Leminski tenha tirado que a poesia é um "inutensílio", ou seja, que todo poema trabalha de um certo modo dentro da lógica da produção material, só que por um sentido do excesso de produtividade que é próprio de uma economia da dádiva, onde o desperdício, o transbordamento, a desmedida e o descontrole são os operadores do consumo, e não a utilidade; ou seja, o valor de uso e o valor de troca. Produção excessiva de sentidos é o trabalho do poeta.

Daí que o poeta no mundo moderno - apesar, et pour cause, da assimetria entre os dois (poeta e mundo moderno) - parece portanto ter se tornado aquilo que Gilles Deleuze e Félix Guattari definiram como "personagem conceitual" e que Agambem indica tomar como ethos argumentativo para sua definição do que é a subjetividade contemporânea. Se Deleuze e Guattari afirmam que há uma "diferença entre personagens conceituais e figuras estéticas [que] consiste de início no seguinte: uns são potências de conceitos, os outros, potências de afectos e perceptos", eles também complementam que "o plano de composição da arte e o plano de imanência da filosofia podem deslizar um no outro" (DELEUZE; GUATTARI, 1992: 87-89). Por isso, torna-se importante perguntar por que caminhos podemos compreender a poesia como uma importante forma de crítica da cultura? E de que forma o poeta ainda pode ser compreendido como um modo de subjetivação que agencia formações discursivas similares ao que é comum no homem anônimo da multidão? Necessário então se torna efetuar diagramas genealógicos de algumas das suas possíveis figurações. Dos andarilhos trovadores da Idade Média aos beatniks norte-americanos da segunda metade do século XX; dos griots africanos e repentistas nordestinos aos cantores da música pop; dos poetas-soldados do humanismo renascentista aos poetas engajados em independências e revoluções modernas; dos poetas místicos, visionários e obscuros aos atuais poetas tecnológicos; dos que dialogam com culturas e tradições extraocidentais pelo viés religioso aos que o fazem pelo viés etnográfico. Enfim, a prática discursiva da poesia se confunde com múltiplos processos histórico-culturais de subjetivação, constituindo o poeta em um 
complexo personagem conceitual, dotado de incontáveis faces, ainda atuais e presentes no imaginário e nas políticas de subjetividade contemporâneas.

Perceber figurações do poeta articuladas aos processos históricos e políticos de subjetivação permite potencializar tanto essa figura modalizadora das subjetividades contemporâneas quanto avaliar alguns lugares e entre-lugares culturais para a poesia dentro da lógica contemporânea. O esforço aqui é o de entrever - através dos poetas articulados em figuras e dos seus discursos - a política de uma "comunidade que vem", isto é, de uma comunidade qualquer, formada pelo encontro de singularidades inconclusas e extemporâneas - não a comunidade enraizada, estável e permanente. Como os poetas, essas singularidades possuem uma política diferente, a política dos que podem afirmar a própria impotência, dos que possuem a potência de não-ser. Se pensarmos que a poesia é o discurso que se recusa a aceitar que a comunicabilidade basta, um discurso que deseja comunicar o incomunicável, o poeta é a subjetividade "fora da moda" e politicamente não-alinhada, a partilhar do sensível de uma outra política. Tal como o escrivão mellvileano Bartleby, uma política da inutilidade, pois quando "o ato perfeito de escrita não provém de uma potência de escrever, mas de uma impotência que se vira para si própria e, deste modo, realiza-se a si como ato puro. [Ele] não escreve outra coisa do que a sua potência de não escrever" (AGAMBEN, 1993: 35).

Hoje, então, os poetas já se tornaram um ethos cujas características discursivas são permanentemente agenciadas para se entender e definir processos de subjetivação do comum que resistem anonimamente à maquinaria de captura semiótica pelo Estado e pelo Capital. É trabalho dos poetas compartilhar linhas de fuga em meio à grande política que o Império midiático-mercadológico de alcance global forja à maneira de uma segunda natureza. Em Multidão (2005), livro-continuação a Império, Toni Negri e Michael Hardt recorreram aos pragmatistas norte-americanos William James e John Dewey para desenvolver uma noção de hábito como possível eixo subjetivo para a produção do comum. Deslocando a subjetividade de um plano transcendental ou de uma profundidade psicológica, com o hábito "eles buscam a subjetividade na experiência, nas práticas e no comportamento diário. (...) Os hábitos criam uma natureza que serve de base para a vida(...) são nossa natureza social” (2005: 257). Os hábitos possuem a ambivalência 
que mescla espontaneidade pretensamente natural e técnicas sociais, das mais imateriais - como certas formas de falar - às mais materiais - como formas e meios de andar, se vestir, dormir, comer, etc. Como não relacionar essa noção de hábito - que "são compartilhados e sociais" - à reflexão que Dominique Maingueneau desenvolve, ao afirmar que "o etos [sic] parece indissociável de uma 'arte de viver', de uma 'maneira global de agir', daquilo que um sociólogo como P. Bourdieu denomina um habitus” (2001: 147). Nas três noções - o hábito pragmático, o ethos retórico-discursivo e o habitus sociológico - imagens de si são construídas a partir de microprocessos discursivos de subjetivação.

Negri e Hardt vão buscar na política queer de Judith Butler o vínculo do hábito com esses microprocessos da performatividade cotidiana: "toda forma de trabalho que produz um bem imaterial, como uma relação ou um afeto, resolvendo problemas ou proporcionando informação, do trabalho de vendas aos serviços financeiros é fundamentalmente uma performance: o produto o próprio ato em si" (2005: 261). Por outro lado, a teoria do ethos em Maingueneau diz que "o etos [sic] implica portanto um policiamento tácito do corpo, uma maneira de habitar o espaço social”, pois a representação do enunciador, que ele chama de "fiador", "possui uma caráter e uma corporalidade" (2001: 139). Essa fiabilidade do sujeito da enunciação, quando implica "caráter" e "corporalidade", faz parte do núcleo da política queer e é um poderoso método de produção micropolítica do comum resistente às grandes políticas da subjetividade, de alcance global nos dias que correm. O minimalismo nas performances cotidianas faz da arte de viver uma arte de poeta, assim como da poesia, um sinônimo de vida. Eis o sonho de todas as vanguardas que fazem valer seu nome, de Stéphane Mallarmé e Antonin Artaud a Herberto Helder e Marina Abramovic.

No poema "Boca de cena primal", Waly Salomão consegue figurar bem o misto de espontaneísmo e artificialismo que a performatividade política do comum demanda e que tem no poeta um Adão voluntariamente decaído, mas livre para "ricas promessas de aventuras":

Adão encena de forma insólita e cristalina

La vida es sueño de Calderón de la Barca. 
Como se estivesse de pé

No proscênio de um palco italiano,

Desobedece à marcação do diretor.

Nenhuma dália para ler.

Avança de olhos abertos.

Estaca.

Cerra os olhos.

Olhos cerrados

Como cortinas fechadas de teatro.

Encara de frente

(olhos cerrados)

a luz desmesurada

Do sol

Que pinta de gelatina vermelha

O ciclorama de suas pálpebras

Ricas de promessas de aventuras.

(SALOMÃO, 1998: 61)

Como ator social, o poeta-performer é visto como alguém que constrói um espaço subjetivo de desenvoltura alternativa perante os poderes sociais ("Desobedece a marcação do diretor", "Cerra os olhos"), tão caracterizados pela mercantilização homogeneizante das sensibilidades e sociabilidades, em que os processos de subjetivação e o imaginário sócio e histórico-cultural são cada vez mais intensamente produzidos por dispositivos midiático-financeiros de alta rotatividade e convenções impositivas ("encena de forma insólita e cristalina", "Como se estivesse de pé / No proscênio de um palco italiano"). Sozinho, sem ajuda ou roteiro ("Nenhuma dália para ler"), nesse terceiro espaço, o anônimo poeta-performer dos nossos dias "Encara de frente / (olhos cerrados) / a luz desmesurada / Do sol", num misto de vida e sonho, produtividade e representação.

Sempre que alguém produz uma obra - incluída aqui a sua própria vida - que pode ser entendida de alguma forma como autônoma e criativamente 
singular, e isso proporciona um tipo de rasura que podemos chamar de experiência do fora - experiência exterior às grandes referências político-culturais, experiência perpendicular em relação ao campo de poder, experiência política originária -, é comum ser qualificado como "poeta”. Por isso o poeta é um ethos cujas "pálpebras [são] / Ricas de promessas de aventuras". Assim ocorre com diretores de cinema, dançarinos, designers, mímicos, arquitetos, revolucionários, cronistas, romancistas e compositores. Todos aventureiros exemplares da subjetividade, aventureiros que - por serem exemplares são comuns, escapam à antinomia do universal e do particular, pertencem ao grupo e ao mesmo tempo dele escapam quando nomeados. Multidão de poetas anônimos.

Por um lado, é lugar-comum no discurso contemporâneo se dizer que a poesia não tem mais lugar na sociedade, que ninguém lê poesia, que poesia não vende e que não pertence à lógica do mercado; assim como na percepção geral é muito comum o poeta ser visto como um misto de clown exibicionista, sonhador utópico, vagabundo crítico e intelectual pretensioso. No entanto, por outro lado, poetas de todas as estirpes, estilos e temperamentos têm buscado formas para rasurar dialogicamente as malhas da comunicação espetacular, massificada e consumista dessa mesma sociedade. Há os que mesclam escrita, tecnologia do som e da imagem, música, tradições culturais específicas, artes plásticas e performances em palco; as que articulam um discurso ambíguo que funde um brutal simplismo sintático e lexical na sua comunicação poética através de tópicas massificadas do imaginário infanto-juvenil com um discreto e irônico discurso de interdição moral-sexual; os que plasmam seu discurso poético ao da tradicional poesia africana, produzindo poderosos poemas etnográficos; aqueles que montam uma persona pública excêntrica e que em livros de poemas (alguns em terceira edição por editoras de porte nacional) produzem performances autoficcionais, abrangendo desde a sua biografia familiar até a assinatura autoral (uma justaposição dos nomes da sua mãe e do seu pai, também poetas conhecidos); aqueles que editam muitos de seus próprios livros de modo semi-artesanal, em pequenas tiragens, pregando uma poesia que chama ironicamente "sem qualidades" por se recusar a cuidados verbais que obscureçam a tensão emocional do sujeito trazida para primeiro plano; aquelas que fazem intervenções 
artísticas em museus e no espaço urbano com poemas, palavras e versos em instalações, grafites e cartazes. Isso sem falar na internet e seu estilhaçar de poemas e poetas através das diversas redes sociais, chamando a atenção para uma verdadeira resistência anônima dos poetas nos tempos que correm, suas tentativas reais de penetração crítica nas novas condições de sociabilidade e de produção do comum pela multidão de singularidades que povoam o mundo. O que há, em suma, é um esforço evidente da poesia de falar no presente para esse público-leitor que João Cabral chamou de "Ninguém". O devir-multidão dos poetas contemporâneos não os torna necessariamente mais visíveis a ninguém - por isso nossa opção de não nomear nenhum dos poetas que acima esboçam formas singulares de performance -, mas torna o público-leitor mais atento ao seu próprio (im)produtivo anonimato, ao seu "fazer para esquecer / que é inútil", ao seu encarar "de frente / (olhos cerrados) / a luz desmesurada / Do sol". Resistindo ao brilho espetacular.

É num ensaio que concentra muitas das suas ideias sobre literatura, chamado "A literatura e a vida", que Gilles Deleuze elabora uma inspiradora reflexão sobre o que é escrever, ao desvincular a escrita de qualquer traço de uma metafísica humanista. Ele é categórico ao afirmar: "A vergonha de ser um homem: haverá razão melhor para escrever?” (DELEUZE, 1993: 11). Com essa afirmação, Deleuze recusa a lógica da representação e opta por uma concepção de escrita baseada numa lógica da produtividade, em que o devir ativa a produção de sentidos enquanto um permanente processo sempre inacabado, informe e em aberto. Daí que Deleuze percebe a existência de séries paralelas ao Ser-Homem, em que de um lado encontramos um devir-mulher, um devir-negro, um devir-ameríndio, um devir-criança, dentre outros, e do outro lado um devir-animal, um devir-vegetal, um devir-molecular até um devir-imperceptível. Deleuze escreve que "mesmo quando é uma mulher que devém, ela tem de devir-mulher, e esse devir nada tem a ver com um estado que ela poderia reivindicar. Devir não é atingir uma forma (...), mas encontrar a zona de vizinhança, de indiscernibilidade ou de indiferenciação" (DELEUZE, 1993: 11). Em outro texto, ele e Guattari chegam a definir devir como "o processo do desejo" (DELEUZE; GUATTARI, 1997: 64). Os devires se dão no momento em que algo se passa entre duas séries, criando essas zonas de contato e contaminação. Por isso eles vão 
sempre repetir que "a literatura é um agenciamento coletivo de enunciação" (DELEUZE, 1993: 15), ou seja, um escritor jamais escreve sozinho, mas povoado de multidões; precisa agenciar subjetividades menores ou mesmo inumanas para fortalecer sua frágil saúde irresistível: "fim último da literatura: pôr em evidência no delírio essa criação de uma saúde, ou essa invenção de um povo, isto é, uma possibilidade de vida. Escrever por esse povo que falta ('por' significa 'em intenção de' e não 'no lugar de')" (DELEUZE, 1993: 15). Nas linhas escritas, na sua sintaxe, no seu léxico, na sua cadeia sonora, o poeta - ainda mais do que o prosador - agencia afetos e sensações em blocos que o arrastam - e aos leitores - intensamente por devires minoritários da multidão.

\section{POETA COMO SUJEITO VULNERÁVEL}

Pedro Paulo de Oliveira identificou o ideal moderno da masculinidade como tendo matrizes históricas no ideal cavalheiresco medieval e em sua ênfase nos laços de sangue e no elevado senso de honra, orgulho e dignidade através de gestos de bravura, ousadia e destemor (cf. OLIVEIRA, 2004: 25). O símbolo da masculinidade medieval centrar-se-ia no duelo e a sua modernização dar-se-ia como transição para o aperto viril de mãos. Aliás, ainda é muito comum se encontrar pessoas que avaliam o caráter de outro - sobretudo de homens - pelo aperto de mãos. Exemplar também é a frase "fio de bigode", que expressa a honra posta em jogo num contrato, tradicionalmente selado com um aperto de mãos. Ou seja, os rituais da nobreza guerreira medieval paulatinamente se aburguesaram, mas não perderam traços de rivalidade e rudeza viris. Serão incorporados pelos exércitos nacionais e associados aos modernos nacionalismos através do que o autor chama de "três 'p' da ideologia masculina": potência, poder e posse (OLIVEIRA, 2004: 27). A militarização da imagem do homem que vai ocorrer ao longo do século XIX alimentará fortemente o imaginário nazifascista da primeira metade do século XX, assim como fundamentará o que Nietzsche - com sua obsessão pela antiga tópica da vita activa - chamará de "a grande política"; isto é, o culto do combate, da luta e do 
ágon ${ }^{2}$. No combate, o mito da perfeição corporal do guerreiro, da sua força e vontade atlética e do seu sacrifício físico e moral são fundamentais. $\mathrm{Na}$ "grande política", necessariamente ativa, bem como na doutrina da força de Nietzsche e no culto ao corpo militarizado dos diversos totalitarismos nacionais ao longo do século XX, há o medo da ideia de uma possível passividade afeminada. Esse mito (ativo/passivo) da lógica binária de pensamento repetiria, segundo Judith Butler,

uma relação entre cultura e natureza pressuposta por alguns modelos do gênero como construção, [supondo] uma cultura ou uma agência do social que age sobre uma natureza, a qual é, ela própria, pressuposta como uma superfície passiva, fora do social, mas sua necessária contraparte. Uma questão que as feministas têm levantado é, pois, a de saber se o discurso que descreve a ação da construção como uma espécie de impressão ou imposição não seria taticamente masculinista, enquanto a figura da superfície passiva esperando aquele ato de penetração pelo qual o significado é atribuído não seria, taticamente, ou - talvez - bastante obviamente feminino. Estará o sexo para o gênero assim como o feminino está para o masculino? (BUTLER, 2000: 156-7)

Diríamos que para o discurso masculinista a pergunta de Butler tem resposta positiva. Trata-se de "degradar o natural como aquilo que existe 'antes' da inteligibilidade, como aquilo que precisa da marca do social, quando não da sua ferida, para significar, para ser conhecido, para adquirir valor" (BUTLER, 2000: 157). Então a permanência da noção de natureza, assim como a de feminino, só sustenta uma necessária hegemonia da noção de cultura,

2 Sobre noção de "grande política" em Nietzsche, ver o aforismo 189, de Aurora, intitulado justamente "A grande política", em que escreve: "Por mais que o proveito e a vaidade, tanto de indivíduos como de povos, possam influir na grande política: a corrente mais forte que a impele é a necessidade do desenvolvimento do poder (...)" (2004: 133). 
vinculada à de masculinidade. Tal relação - hierarquizante e naturalizada entre o homem e a masculinidade como ativos e a mulher e a feminilidade como passivos - estrutura o espaço público e as formas de política como se dominados por uma vontade de poder, e é ironicamente alegorizada ao longo do poema "Poetisa-fêmea, poeta-macho (cliché em papel couché)" de Adília Lopes:

Sou uma poetisa-fêmea

falo do falo

Sou um poeta-macho

sacho

3

Sou um poeta-macho

sou um desmancha-prazeres

sou um empata-fodas

Sou uma poetisa-fêmea para mim

é tudo bestial

4

Sou um poeta-macho

sou arrogante

sou um pé de Dante

Sou um poeta-macho

sou um facto

sou um fato

5

Sou um poeta-macho

tenho um gabinete 
sou uma poetisa-fêmea

escrevo na retrete

Sou um poeta-macho

sou um badalo

sou uma poetisa-fêmea

calo-me

6

A poetisa-fêmea

toca viola

o poeta-macho

viola-a [...]

(LOPES, 1999: 462-3)

O que definiria o "poeta-macho" seriam justamente signos dos "três 'p' da ideologia masculina": a potência ("sacho", "badalo"), o poder ("desmancha-prazeres", "empata-fodas", "violo-a") e a posse ("tenho um gabinete"), dando-lhe autoridade, seriedade, força, profissionalismo, eficiência, assertividade e presença. Já a "poetisa-fêmea" definir-se-ia pela fala ("falo") e pelo silêncio ("calo-me"), pela inutilidade prazerosa ("toco viola") ou desprazerosa ("tudo é bestial") e pela sujeira, vulgaridade e intimidade ("retrete"), por mais que ali a "poetisa-fêmea" efetivamente escreva (ao contrário do "poeta-macho"). A ironia de Adília está em usar ambas as definições para si própria, dimensionando perfeitamente a necessidade de nos pautarmos todos como "homens masculinos" e "poetas-machos" invulneráveis para sermos levados a sério no espaço público e termos nosso discurso considerado. É essa necessidade que Adília rasura com sua calculada fragilidade, na radical adesão a uma imagem pública de "poetisa-fêmea", mesmo sob o risco de sacrificar a sua própria poesia, mesmo fazendo disso o traço principal da sua poesia. Escreve Rosa Maria Martelo que Adília Lopes tem pagado o preço "mesmo junto de quem leva inteiramente a sério a sua poesia: é que, 
de uma maneira ou de outra, enquanto figuração autoral que consente uma leitura autobiográfica, Adília Lopes apresenta-se sempre desarmada pela sua imagem de anti-poeta menina" e de que "perdida essa tensão, o que fica é a imagem infantilizada” (MARTELO, 2010: 243-4).

Ou seja, a performance com que Adília Lopes - de resto, um pseudônimo autoral de Maria José da Silva Viana Fidalgo de Oliveira: o que revelaria uma encenação de "gabinete", ou seja, masculina? - marca a sua subjetivação ao longo de mais de vinte livros de poemas transmite a mesma ideia da imagem de uma "poetisa-fêmea" calada, tocando viola e escrevendo na retrete: vulnerabilidade ${ }^{3}$. Com essa imagem em particular, Adília coloca entre aspas não apenas o falocentrismo da sociedade patriarcal, mas o próprio campo literário enquanto ethos eminentemente masculino e espaço público de manifestação e legitimação dos escritores. Adília questiona o próprio sentido do que é fazer literatura e política - e literatura política. Intervir publicamente só é visto como possível comumente através de um discurso assertivo de matriz falocrática - simulacro retórico da guerra; mas ela nos permite elaborar uma imagem de vulnerabilidade que também pode ser uma imagem politicamente eficaz ("falo do falo"), e que não tem a guerra e o ágon como modelos de ação.

Para não fazermos dessa posição da "poetisa-fêmea" a posição de toda mulher, destacamos o que ocorre com o discurso político da poesia de Luiza Neto Jorge, que adota uma maior ambivalência com relação ao campo do poder falocrático. Como não lembrar, pelo "falo" de Adília, do "falo" de Luiza, muito diferentes: o desta - em plena deflagração da Guerra Colonial contra o imperialismo português sustentado pelo regime fascista do Estado Novo - Luiza sabia da necessidade contextual de se assumir a "natureza agonística dos atos de dizer e viver" (ORNELLAS, 2010: 131). Luiza foi uma poeta

\footnotetext{
3 Sobre a relação arte-vulnerabilidade-subjetividade, cf. Suely Rolnik (2008), que escreve em "Geopolítica da cafetinagem" que "um dos problemas visados pelas práticas artísticas tem sido a anestesia da vulnerabilidade ao outro, própria da política de subjetivação em curso - anestesia tanto mais nefasta quanto esse outro é representado como hierarquicamente inferior na cartografia estabelecida, por sua condição econômica, social, racial ou outra qualquer. É que a vulnerabilidade é condição para que o outro deixe de ser simplesmente objeto de projeção de imagens pré-estabelecidas e possa se tornar uma presença viva, com a qual construiremos nossos territórios de existência e os contornos cambiantes de nossa subjetividade" (p. 27).
} 
portuguesa que soube dizer isso nos versos da segunda estrofe de "Poema": "falo / com uma agulha de sangue / a coser-me todo o corpo / à garganta" (JORGE, 1973: 47). Aqui, a duplicidade semântica de "falo" indiferencia o dizer do poder, e ambos agem sobre o corpo vulnerável como a violência inescapável de uma "agulha de sangue", seja aquela advinda do poder fálico, seja aquela que o sujeito submete a si próprio para ser dono da sua voz ("a coser-me todo o corpo / à garganta"). Com o "falo do falo" de Adília, ao contrário, está marcado, pelo espaçamento em branco, a diferença entre as duas instâncias, entre os dois sujeitos (o que fala e o do falo), evitando os deslizamentos que irão acontecer em outras instâncias - no âmbito discursivo, e não no textual.

O poeta e poesia contemporâneos estão colados à micropolítica presente na plasticidade dos corpos vivos e na subjetividade vulnerável. Georges Bataille, por exemplo, afirmará em A experiência interior: "ausência de decisão, o poeta é mulher" (1992: 46). Nessa analogia, Bataille toma a poesia como eixo metafórico para uma misógina experiência de indecisão que ele liga à mulher. No entanto, em tempos - como os nossos - de violência masculinista e competitividade capitalista (ou vice-versa: violência capitalista e competitividade masculinista), tal analogia ganha a performatividade de uma política de gênero queer ${ }^{4}$, fazendo dos/as poetas subjetividades criativamente vulneráveis ou, por outra, ativamente passivas: "Ah, poder exprimir-me todo como um motor se exprime! / Ser completo como uma máquina! / Poder ir na vida triunfante como um automóvel último-modelo! / Poder ao menos penetrar-me fisicamente de tudo isto, / Rasgar-me todo, abrir-me completamente, tornar-me passento / A todos os perfumes de óleos e calo-

4 Cf. o artigo da filósofa argentina Beatriz Preciado, "Multidões queer: notas para uma política dos 'anormais"' (2011), em que ela diz: "De noção posta ao serviço de uma política da reprodução da vida sexual, o gênero se torna o indício de uma multidão. O gênero não é o efeito de um sistema fechado de poder nem uma ideia que recai sobre a matéria passiva, mas o nome do conjunto de dispositivos sexopolíticos (...) que serão o objeto de uma reapropriação pelas minorias sexuais. (...) O corpo não é um dado passivo sobre o qual age o biopoder, mas antes a potência mesma que torna possível a incorporação prostética [sic] dos gêneros. A sexopolítica torna-se não somente um lugar de poder, mas, sobretudo, o espaço de uma criação na qual se sucedem e se justapõem os movimentos feministas, homossexuais, transexuais, intersexuais, transgêneros, chicanas, pós-coloniais... As minorias sexuais tornam-se multidões. O monstro sexual que tem por nome multidão torna-se queer". 
res e carvões" (PESSOA, 2007: 79, grifo meu), escreve Álvaro de Campos, o heterônimo de Fernando Pessoa cujas odes modernistas Irene Ramalho Santos nomeia como intersexuais (cf. 2007: 209-29).

Assim, a figura majoritária do poeta político e revolucionário - modernização do poeta-soldado renascentista (cf. REBELO, 1983) - sofreria um abalo e deslocamento quanto a sua presença pública diante de um discurso minoritário, cuja lógica vulneravelmente criativa de comunicação tornar-se-ia uma política de subjetivação do comum - e portanto resistente - em relação às formas duras de comunicação, controle e sociabilidade; formas falsamente transparentes; formas que dominam o espaço público e obrigam todos a se comportar quando nele; formas moralizantes e impositivas. Daí que o mesmo Bataille afirmará, no clássico ensaio "A noção de despesa", que "o termo poesia (...) significa, com efeito, do modo mais preciso, criação por meio da perda”, o que acaba por transformar a figura do poeta em um sujeito cuja

despesa poética deixa de ser [meramente] simbólica em suas consequências: assim, em certa medida, a função de representação empenha a própria vida daquele que a assume. Ela o consagra às mais falazes formas de atividade, de miséria, ao desespero, à persecução de sombras inconsistentes que nada podem dar além da vertigem e do furor. Frequentemente só podem dispor das palavras para sua própria perda, é obrigado a escolher entre um destino que faz de um homem um rejeitado, tão profundamente separado da sociedade quanto os dejetos da vida aparente, e uma renúncia cujo preço é uma atividade medíocre, subordinada a necessidades vulgares e superficiais

(BATAILLE, 1975: 32-3).

Escrever poesia e ser reconhecido publicamente poeta, portanto, é se avizinhar do que há de vulnerável na vida, é tornar-se poderosamente anônimo em meio ao espetáculo público. E assim deixar-se afetar pelas pe- 
quenas precariedades, misérias, manias, desesperos, inocências, loucuras, persecuções, mas também pelos pequenos prazeres, paixões, saberes cotidianos, simpatias, utopias, sonhos, dando razão ao que hoje se chama de crítica biográfica. Mesmo um mestre da crítica formalista como Roman Jakobson percebeu isso com o suicídio do seu amigo Vladimir Maiakovski, escrevendo um belo ensaio sobre como nos poetas escrita e vida se confundem por vias invisíveis, como invisíveis são os espaços de comunicabilidade da multidão: “(...) é absolutamente impossível concluir por uma necessária desvinculação entre a vida do artista e sua arte. (...) Maiakovski compreendia perfeitamente a estreita ligação entre biografia e poesia" (JAKOBSON, 2006: 39-40). O exemplo-limite de Maiakovski diante da "grande política" bolchevique nos faz pensar numa política que, quando feita na clave menor dos poetas, deseja transformar o espaço público em um espaço de criação e vida (não de destruição e morte), espaço de obliquidades (não de assertividades), de ex-centricidades (não de centralismos), de acolhimentos (não de autocracias), de fragilidades (não de fortalezas), de incertezas (não de certezas). E todas repletas do mesmo comum que recentemente o poeta norte-americano Charles Bernstein elaborou no livro Girly man (2006), cujo título faz referência a uma declaração do então governador da Califórnia Arnold Schwarzenegger - sobre os que eram contra a chamada "Guerra ao Terror" no Pós-11 de Setembro. No poema "A balada do afeminado" ("The ballad of the girly man"), Bernstein afirma logo ao início:

A verdade jaz debaixo do choro

Com o medo, a casca do luto vira couro

Uma democracia adulta

Definha e se torna suja

Por brutamontes que odiar

Preferem em lugar de rimar

(BERNSTEIN, 2006)

Bernstein estabelece uma oposição entre a brutalidade viril e a rima poética. De um lado, o masculinismo totalitário que sufoca a democracia de- 
baixo do choro vingativo ante do horror das mortes no 11 de setembro; de outro lado, o devir-vulnerável que o poeta invoca como performance de resistência à violência política que "repete o erro do horror":

Então seja afeminado

Assuma um jeito viado

Cante uma canção libertina

E dance com saia de menina

Poesia não vence a guerra contra o terror

Mas também não repete o erro do horror

Nós afeminados não tememos

Razão, interdependência ou incerteza

Usamos antes e depois da luta a cabeça

Rezamos por bom senso, arte e compromisso ${ }^{5}$

(BERNSTEIN, 2006)

Da performance queer que é dançar "com saia de menina" (with a girly sarong), passando pela fragilidade da poesia em vencer a "guerra ao terror", até o compromisso político com a sensibilidade, o percurso da poesia se contrapõe decididamente ao discurso da moderna masculinidade como definidora da prática pública - que até aqui neste texto é identificado com Arnold Schwarzenegger, com a estética militar dos regimes nacionalistas e com discursos de assertividade totalitária. Podemos até dizer que essas três imagens da invulnerabilidade masculinidade hoje de certa maneira se encontram presentes na lógica biopolítica do celebrity system, pela qual a

5 Os versos originais - cuja tradução é minha - são: "The truth is hidden in a veil of tears / The scabs of the mourners grow thick with fear // A democracy once proposed / Is slimmed and grimed again / By men with brute design / Who prefer hate to rime // (...) // So be a girly man / \& take a gurly stand / Sing a gurly song / \& dance with a girly sarong // Poetry will never win the war on terror / But neither will error abetted by error // We girly men are not afraid / Of uncertainty or reason or interdependence / We think before we fight, then think some more / Proclaim our faith in listening, in art, in compromise // (...)" (BERNSTEIN, 2006: 179-80). 
invisibilidade e o anonimato correspondem à morte. Talvez não seja mero acaso o ideal moderno de masculinidade ter sido publicamente reafirmado em um contexto de guerra e paranoia norte-americanas por uma personalidade tão típica desse sistema como Arnold Schwarzenegger. Encarnando anteriormente o Mister Universo, Conan, o Bárbaro, e o Exterminador do Futuro, o então Governador da Califórnia pareceu desconhecer a irônica lição de Emily Dickinson: "Não sou Ninguém! Quem é você? / Ninguém Também? / Então somos um par? / Não conte! Podem espalhar!”. Diante do terror vazio da celebrização, prezar pelo anonimato e pela discrição talvez seja a mais poderosa fórmula que o devir-vulnerável da poesia de Emily Dickinson - "Que triste - ser - Alguém! / Que pública - a Fama - / Dizer seu nome - como a Rã - / Para as almas da Lama!”6 (DICKINSON, 2008: 41) - pode nos ensinar: uma política menor e ativamente passiva. Sem gestos salvacionistas, universais e totalitários. Daí que a "grande política" - de matriz eminentemente falocêntrica - se organiza com base em um regime discursivo de inflexibilidade, virilidade e força que incide principalmente sobre mulheres e sujeitos queer, mas não deixa de também cair sobre os próprios homens heterossexuais, maiores vítimas de mortes violentas segundo estatísticas brasileiras (cf. IBGE, 2013).

São as políticas de subjetivação que permitem dar espessura verdadeiramente discursiva a figurações e devires de poetas. E dizer que o/a poeta é vulnerável significa encará-lo/a como uma subjetivação performática que desloca o sentido de muitas práticas políticas. Destacar o devir-vulnerável que é performatizado pelo plano de composição da poesia contemporânea é o mesmo que reafirmar com Deleuze que a melhor razão para escrever é “a vergonha de ser um homem”. Deleuze sustenta que na arte da escrita está em jogo uma insatisfação com os lugares discursivos institucionais, lugares de poder, lugares falocráticos, e que o devir, isto é, o desejo de tornar-se outro, é o que leva alguém a escrever-e-ler poesia. Se tomarmos categorias topológicas como interioridade e exterioridade, as subjetividades falocêntricas

\footnotetext{
6 A tradução é de Augusto de Campos sobre o seguinte texto original: "I'm nobody! Who are you? / Are you nobody, too? / Then there's a pair of us - don't tell! / They'd banish us, you know. // How dreary to be somebody! / How public, like a frog / To tell your name the livelong day / To an admiring bog!” (DICKINSON, 2008: 40)
} 
podem ser compreendidas como um ideal histórico de profundidade baseado numa ideia de natureza interior que oprime a vulnerável plasticidade do exterior; de um lado, a inflexível verdade da metafísica: o Ser, o Ideal, a Masculinidade; de outro lado, a plástica verdade da estética: o devir, o real, a feminilidade; no meio, os poetas e seu discurso vulnerável, relacionando-se com ambos não como polos opositivos, mas como duas séries dentre várias que permitem arranjos complexos e variações infinitas na prática discursiva de subjetivações de que é feita a poesia.

\section{REFERÊNCIAS BIBLIOGRÁFICAS}

AGAMBEN, Giorgio. A comunidade que vem. Lisboa: Presença, 1993.

AGAMBEN, Giorgio. O que é o contemporâneo? e outros ensaios. Florianópolis: Argos, 2009.

BATAILLE, George. A parte maldita; precedida de A noção de despesa. Rio de Janeiro: Imago, 1975.

BATAILLE, George. A experiência interior. São Paulo: Ática, 1992.

BERNSTEIN, Charles. Girly man. Chicago: The University of Chicago Press, 2006.

BUTLER, Judith. Corpos que pesam: sobre os limites discursivos do "sexo". In. LOURO, Guacira Lopes (Org.). O corpo educado: pedagogias da sexualidade. 2 ed. Belo Horizonte: Autêntica, 2000. p. 151-168.

DELEUZE, Gilles. A literatura e a vida. Crítica e clínica. Rio de Janeiro: 1993. p. 11-6.

DELEUZE, Gilles, GUATTARI, Félix. O que é a filosofia?. Rio de Janeiro: Ed. 34, 1992. 
DELEUZE, Gilles, GUATTARI, Félix. Devir-intenso, devir-animal, devir-imperceptível... Mil platôs. São Paulo: Ed. 34, 1997. vol. 4, p. 11-114.

DICKINSON, Emily. Não sou Ninguém. Trad. Augusto de Campos. Campinas-SP, EDUNICAMP, 2008. Ed. bilíngue.

GLENADEL, Paula. O valor da poesia. São Paulo: Lumme Editor, 2010.

HARDT, Michael, NEGRI, Antonio. Multidão. Rio de Janeiro: Record, 2005.

INSTITUTO BRASILEIRO DE GEOGRAFIA E ESTATÍSTICA. A população jovem no Brasil: a dimensão demográfica. Disponível em: http://www. ibge.gov.br/home/estatistica/populacao/populacao_jovem_brasil/comentario1.pdf. Acesso em: 11mar. 2013.

IVO, Lêdo. A ética da aventura. Rio de Janeiro: Francisco Alves, 1982.

JAKOBSON, Roman. A geração que esbanjou seus poetas. São Paulo: Cosac Naify, 2006.

JORGE, Luiza Neto. Sítios sitiados (1960-1970). Lisboa: Plátano, 1973.

LOPES, Adília. Dobra. Poesia reunida. Lisboa: Assírio e Alvim, 2009.

MAINGUENEAU, Dominique. O contexto da obra literária: enunciação, escritor, sociedade. 2 ed. São Paulo: Martins Fontes, 2001.

MARTELO, Rosa Maria. As armas desarmantes de Adília. A forma informe: leituras de poesia. Lisboa: Assírio e Alvim, 2010. p. 235-52.

MELO NETO, João Cabral de. Museu de tudo. Obra completa. Rio de Janeiro: Nova Aguilar, 1994. 
NIETZSCHE, Friedrich. Aurora. São Paulo, Companhia das Letras, 2004.

OLIVEIRA, Pedro Paulo de. A construção social da masculinidade. Belo Horizonte: EDUFMG, 2004. ORNELLAS, Sandro. Re-luzir Luiza. Quinto Império. Salvador: Quarteto Editora, 2010. Gabinete Português de Leitura, vol. 01, n. 23, p. 123-40. PESSOA, Fernando. Ode Triunfal. Poemas de Álvaro de Campos. Ed. de Teresa Rita Lopes. São Paulo: Companhia das Letras, 2007. p. 78-86.

PRECIADO, Beatriz. Multidões queer: notas para uma política dos anormais. Revista Estudos Feministas, UFSC. Florianópolis, vol. 19, n.1, jan./ apr. 2011. Disponível em: <http://www.scielo.br/scielo.php?pid=S0104-026X2011000100002\&script=sci_arttext>. Acesso em: 11 mar. 2013.

REBELO, Luís de Sousa. Armas e letras: um topos do humanismo cívico. In: A tradição clássica na literatura portuguesa. Lisboa: Horizonte Universitário, 1982. p. 195-240.

ROLNIK, Suely. Geopolítica da cafetinagem. In. FURTADO, Beatriz, LINS, Daniel (Org.) Fazendo rizoma. São Paulo: Hedra, 2008. p. 25-44.

SALOMÃO, Waly. Lábia. Rio de Janeiro: Rocco, 1998.

SANTOS, Irene Ramalho. Intersexualidades e a Ode Modernista: os poemas do mar de Pessoa e Crane. Poetas do Atlântico. Fernando Pessoa e o modernismo anglo-americano. Belo Horizonte: EDUFMG, 2007. p. 191-242. 